Discussion Paper No. 18-050

\title{
Unbundling, Regulation and Pricing:
} Evidence from Electricity Distribution

Sven Heim, Bastian Krieger, and Mario Liebensteiner

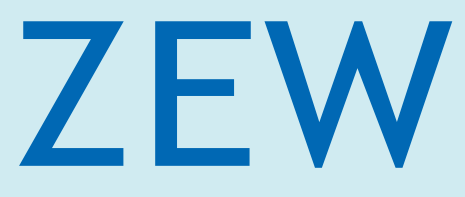

Zentrum für Europäische Wirtschaftsforschung $\mathrm{GmbH}$ Centre for European Economic Research 
Discussion Paper No. 18-050

\title{
Unbundling, Regulation and Pricing: Evidence from Electricity Distribution
}

\author{
Sven Heim, Bastian Krieger, \\ and Mario Liebensteiner
}

Download this ZEW Discussion Paper from our ftp server:

http://ftp.zew.de/pub/zew-docs/dp/dp18050.pdf

Die Discussion Papers dienen einer möglichst schnellen Verbreitung von neueren Forschungsarbeiten des ZEW. Die Beiträge liegen in alleiniger Verantwortung der Autoren und stellen nicht notwendigerweise die Meinung des ZEW dar.

Discussion Papers are intended to make results of ZEW research promptly available to other economists in order to encourage discussion and suggestions for revisions. The authors are solely responsible for the contents which do not necessarily represent the opinion of the ZEW. 


\title{
Unbundling, Regulation and Pricing: Evidence from Electricity Distribution*
}

\author{
Sven Heim ${ }^{\dagger} \quad$ Bastian Krieger ${ }^{\ddagger} \quad$ Mario Liebensteiner ${ }^{\S}$
}

November 1, 2018

\begin{abstract}
Unbundling of vertically integrated utilities has become an integral element in the regulation of network industries and has been implemented in many jurisdictions. The idea of separating the network, as the natural monopoly, from downstream retailing, which may be exposed to competition, is still subject to contentious debate. This is because there is much empirical evidence that unbundling eliminates economies of vertical integration while empirical evidence on price reducing effects is still lacking. In this paper we study the effect of legal unbundling on grid charges in the German electricity distribution industry. Using panel data on German distribution system operators (DSOs) we exploit the variation in the timing of the implementation of legal unbundling and the fact that not all DSOs had to implement unbundling measures. We are also able to identify heterogeneous effects of legal unbundling for different types of price regulation, because we observe a switch in the price regulation regime from rate-of-return regulation to incentive regulation during our observation period. Our findings suggest that legal unbundling of the network stage significantly decreases grid charges in the range of $5 \%$ to $9 \%$, depending on the type of price regulation in place.
\end{abstract}

Keywords: Vertical Integration; Electricity Distribution; Unbundling; Regulation

JEL Classification: D22, L11, L22, L51, L94, Q48

\footnotetext{
${ }^{*}$ We gratefully thank ene't for providing us the data on distribution grid charges and characteristics.

${ }^{\dagger}$ Mines ParisTech (CERNA), PSL Research University, Paris, and ZEW Centre for European Economic Research Mannheim; E-Mail: sven.heim@mines-paristech.fr

${ }^{\ddagger}$ ZEW Centre for European Economic Research Mannheim; E-mail: bastian.krieger@zew.de

${ }^{\S}$ University of Kaiserslautern; E-Mail: mario.liebensteiner@wiwi.uni-kl.de
} 


\section{Introduction}

Unbundling of vertically integrated utilities (VIU) has become a major instrument when it comes to the regulation of network industries. Given that the network represents an essential input for downstream retailers, VIUs may have incentives to discriminate the network access against retail competitors by setting high grid charges, while the VIUs themselves can crosssubsidize these costs. Thus, unbundling of the network stage intends to limit the incentives for discrimination of the former VIU and to foster competition in the retail segment. Despite its potential benefits, unbundling remains a controversial topic. The reason is that it causes a loss of vertical economies of scope while evidence on whether its potential benefits e.g. lower pricesas lower materialize in practice is still lacking.

In the past two decades, the regulatory principle of vertical divestiture in combination with third party access has been applied in a variety of forms in many infrastructure industries, especially in electricity markets, around the globe. For instance, the European Union requires legal unbundling of the electricity and gas distribution networks for VIUs with more than 100,000 customers. ${ }^{1}$ The unbundled distribution system operator (DSO) must be independent with respect to its legal form, organization, and decision making from other activities not related to distribution (CEER, 2013). Ownership unbundling of the electricity and gas transmission network has been compulsory for EU Member States since the Third Energy Package came into force in 2009. Not only in Europe but also in the US, unbundling is widely applied in the electricity and natural gas industries (Höffler and Kranz, 2011b). Besides in energy markets, vertical unbundling is also practiced in many other infrastructure markets such as railway transportation (van de Velde, 2015; Finger, 2014), telecommunications (Bourreau and Doğan, 2005; Pindyck, 2007), and internet broadband (Nardotto et al., 2015).

However, despite its wide application and now more than one decade of experience with unbundling measures in many industries, empirical evidence on its competition fostering effects is still scarce. Moreover, there is a body of empirical literature highlighting that unbundling may lead to the loss of vertical economies, which particularly deals with ownership unbundling (see, e.g., Arocena et al., 2012; Gugler et al., 2017; Triebs et al., 2016, for recent contributions). Also, economic theory suggests that unbundling may lead to reduced investments in the network in order to increase equilibrium prices (e.g. Buehler et al., 2004; Cremer et al., 2006; Gugler

\footnotetext{
${ }^{1}$ Electricity Directives 2003/54/EC, 2009/72/EC, and Gas Directives Directive Directive 2003/55/EC, 2009/73/EC.
} 
et al., 2013). Because of these two counteracting affects - ambigous effects on prices on the one hand and a loss of vertical economies on the other - there is still a controversial debate among scholars and policy-makers about the costs and benefits of unbundling. For example, Japan's announcement in 2015 to legally unbundle its electricity transmission and distribution sector by April 2020 has received much media attention, in which the unpredictable effects are often criticized. ${ }^{2}$ However, some theoretical papers argue that legal unbundling may serve as a 'golden mean' between full ownership unbundling and vertical integration as it minimizes the loss in vertical economies but is supposed to be similarly effective in fostering competition (see, e.g. Höffler and Kranz, 2011b). But again, empirical evidence is lacking and it is frequently questioned if LU is actually effective in fostering downstream competition.

To reduce this void in the literature, we study the competitive effect of legal unbundling in the German electricity distribution industry on grid charges. We make use of the fact that VIUs with more than 100,000 customers had to legally unbundle, while utilities below this threshold have been allowed to stay vertically integrated. Moreover, we have additional variation in the implementation of unbundling measures as not all DSOs implemented legal unbundling in the same year. A key feature is our exhaustive panel dataset on grid charges and firm and network characteristics of German DSOs. The sample period 2005-2014 covers the unbundling transition of several DSOs. In addition, our sample covers an important regulatory change, a switch from rate-of-return regulation to incentive regulation. Hence, we test the effect of legal unbundling on grid charges under different types of price regulation using a triple-differences approach. Another feature of our paper is that we are able to match DSOs with the generation capacity of intermittent renewable energy sources connected to their grid. The connection of decentralized solar and wind plants poses a new challenge to DSOs and may significantly drive their costs.

We find that the implementation of legal unbundling leads to a decrease in distribution grid charges in the range of $5 \%$ to $9 \%$, depending on the on the type of price regulation. During rate-of-return regulation, firms subject to legal unbundling set around $5 \%$ lower prices. After 2009, when incentive regulation was introduced in the German electricity distribution sector, legally unbundled firms charge even $9 \%$ lower prices than vertically integrated utilitities. The results remain robust in several robustness checks, such as Lewbel (2012)'s heteroskedasticitybased instrumental variables approach, split sample analyses, dropping DSOs that unbundled

\footnotetext{
${ }^{2}$ For critical reactions, see e.g.: IEEE Spectrum, March 30, 2016: "Consequences of Japan's Energy Market Reforms Not Easy to Predict", site access on October 5, 2018.
} 
voluntarily, as well as running placebo tests.

To sum up, our results show that legal unbundling is indeed effective in reducing grid charges. However, the results also suggest that the magnitude of the price reducing effect depends on the price regulation regime in place and is significantly more pronounced under incentive regulation than under rate-of-return regulation. From this perspective, our results are 'good news' to many jurisdictions that already apply legal unbundling in combination with incentive regulation. For example, this combinations applies to electricity and gas distribution markets in most EU Member States and in many States of the USA. For Japan, currently planning to introduce legal unbundling, our results may be promising.

The remainder of this paper is structured as follows. Section 2 provides background knowledge about the German electricity sector and its regulatory reforms and Section 3 provides an overview of the relevant literature. Our data are presented in Section 4 and our identification strategy and the results in Section 5. Section 6 summarizes and provides conclusions.

\section{Industry Background}

The electricity supply chain can be briefly segregated into generation, high-voltage supraregional transmission, lower-voltage local distribution, and downstream retail. In Germany, electricity generation is divided between four major electricity utilities (i.e. RWE, EnBW, E.ON, Vattenfall) operating the vast majority of generation capacity, and several local producers as well as foreign companies. ${ }^{3}$ However, the historically high market concentration of the four big players has decreased in recent years, mainly for two reasons. Firstly, as a political consequence to the nuclear plant accident in Fukushima in 2011, six gigawatt of their nuclear generation capacity was shut-down. Secondly, a strongly growing deployment of generation capacity from decentralized RES in Germany reduces the share of conventional electricity generation capacity. ${ }^{4}$

Germany is subdivided into four transmission grid areas operated by 50 Hertz Transmission, TransnetBW, Amprion and TenneT TSO. These transmission grid operators (TSOs) emerged from the ownership unbundling of the four major German electricity utilities. ${ }^{5}$ Electricity

\footnotetext{
${ }^{3}$ According to the special reports 59 and 71 of the German Monopoly Commission (2011, 2015), the Big Four covered 82 percent of the overall electricity generation capacity in 2009 and 62 percent of the nuclear power and fossil fuels electricity generation capacity in 2014 .

${ }^{4}$ Electricity generation from renewable energies such as wind and solar is heavily subsidized by the Renewable Energy Act (in German: "Erneuerbare Energien Gesetz" (EEG)).

${ }^{5} 50$ Hertz from Vattenfall, TransnetBW from EnBW, Amprion from RWE and TenneT from E.ON.
} 
distribution is divided between approximately 880 local DSOs (Bundesnetzagentur, 2015). As a result of the high (sunk) costs of building a new electricity grid, competition cannot emerge in this sector. For historical reasons, DSOs are typically part of a vertically integrated utility, which bears the incentive for price discrimination and to exercise non-price discriminatory measures against downstream retail competitors.

To prevent excessively high grid charges, the grid charges were subject to a rate-of-return regulation, which was replaced by an incentive regulation in 2009. ${ }^{6}$ Both regulations involved the prohibition of price discrimination between similar customers and included revenue caps set by the Federal Network Agency. Thus, grid charges are essentially determined by the annual revenue caps, which are set by the regulatory authority at the beginning of each fiveyear regulatory period. ${ }^{7}$ However, the setting of the cap differs fundamentally between the two regulatory regimes. Under rate-of-return regulation, revenue caps were purely cost-based. Hence, DSOs hardly had incentives to become more efficient because any investments or cost changes related to the network operations were accounted for in the revenue cap and did not change their rate of return.

This is in stark contrast to incentive regulation, in which the revenue caps are based on productivity and efficiency estimations to simulate competitive pressure in the regulated industry. The annual revenue cap under incentive regulation consists of two parts. The 'general X-factor' applies equally to all DSOs in the industry and essentially covers the productivity growth in the regulated industry (Gugler and Liebensteiner, 2018). A second DSO-specific component is based on the DSO's (in)efficiency score as determined in a benchmarking process. The idea is that inefficient DSOs get a lower revenue cap as a 'motivation' to become more efficient (i.e. to catch up to the efficiency frontier). Also, in case of network investments or other unforeseen events, DSOs have the right to claim an adjustment of their revenue cap at the regulatory agency. Essentially, the individual revenue cap determines a DSO's scope of price setting for access to its distribution grid. ${ }^{8}$ A price set too high would result in a revenue above the revenue cap that

\footnotetext{
${ }^{6}$ A detailed description of the regulation of grid charges in Germany's electricity distribution sector is provided by the Federal Network Regulation Agency: www.bundesnetzagentur.de/EN/Areas/Energy/Companies/ GeneralInformationOnEnergyRegulation/IncentiveRegulation/IncentiveRegulation_node.html, accessed on September 27, 2018. Also, detailed information can be found in Hellwig et al. (2018).

${ }^{7}$ For the setting of the revenue cap, the regulatory agency examines a DSO's costs for operating the grid, as well as other costs that are not under the immediate control of the DSO (e.g. legal obligations, concession fees, business taxes, upstream transmission charges, investments related to network operations, extra costs of underground cabling, or collective agreements about nonwage and social benefits).

${ }^{8}$ Before a new grid charge enters into force, it has to be reported to the regulatory authority. The regulatory authority then proves whether the grid charge accords with the legal framework, the non-discrimination policy, and commits to a "fair price setting rule."
} 
cannot be retained, while a low price might yield suboptimal profits (RAP, 2014). ${ }^{9}$ Thus, under both regulatory regimes (rate-of-return regulation and incentive regulation), utilities have scope for setting their grid charges, although the revenue cap plays a central role.

With the 2005 novel of the German Energy Law (Energiewirtschaftsgesetz, EnWG) the EU Electricity Directives 2003/54/EC was transposed into national law which required DSOs to legally unbundle from downstream retail. Legal unbundling, however, is only mandatory for utilities with more than 100,000 customers. Only 45 of around 880 DSOs are large enough to fall under legal unbundling requirements in Germany in 2015 (Bundesnetzagentur, 2015). Smaller utilities are exempt from this regulation, as a result of the amount of structural changes required, and are thus still allowed to remain vertically integrated. Although these small utilities have the right to voluntarily legally unbundle, this rarely happens in practice, as outlined in more detail in Section 4. Legal unbundling represents an intermediate approach between the extreme forms of full vertical divestiture (ownership unbundling) and vertical integration. It forces vertically integrated utilities to partition their distribution activities by creating a new legal entity. Using this approach, the distribution grid can remain in the ownership of the integrated enterprise, but it must be managed by a legally distinct DSO. Legal unbundling is thus intended to foster downstream competition by strengthening the formal independence and self-responsibility of the DSO but at the same time mantain the vertical economies as much as possible.

One argument for legal unbundling is that - in contrast to ownership unbundling - the initially VIU may not lose its vertical economies to full extent. Furthermore, legal unbundling is easier to implement in practice, because the unbundled DSO remains in the ownership of the initially VIU. ${ }^{10}$ It is assumed that with full ownership unbundling, the new system operator may be fully neutral against any downstream retailer. However, with legal unbundling the integrated utility still possesses the network even though it must be managed by a legally independent operator. Hence, it is possible that incentives to discriminate, such as setting high grid charges to harm downstream competitors, may sustain with legal unbundling. It is thus open to empirical investigation whether legal unbundling is indeed successful in reducing grid charges compared to vertical integration.

\footnotetext{
${ }^{9}$ Obtained revenues above or below the actual revenue cap are transferred to a regulatory account and transferred at the end of the regulatory period.

${ }^{10}$ Most transmission system operators (TSOs) in Europe are subject to ownership unbundling. One reason may be that only few TSOs exist (usually one per country; four in Germany) so that ownership unbundling is feasible, while with many DSOs (e.g. there are around 880 DSOs in Germany, of which around 45 are large enough to fall under legal unbundling requirements; see also Section 4) the costs of ownership unbundling would be tremendous.
} 


\section{Literature}

We now survey the literature on the different effects of unbundling in the energy sectors: on grid charges, on investments, on retail prices, on economies of scope and on cost efficiency.

The only empirical paper we are aware of that (directly) examines the effect of unbundling measures on grid charges itself is Nikogosian and Veith (2012). They analyze German DSOs using cross-section data from August 2008 but do not find statistically significant effects of required legal unbundling and of ownership unbundling on grid charges. However, they find that voluntariliy unbundled DSOs charge higher prices. Although this paper is related to our analysis, their results are likely to suffer from substantial unobserved heterogeneity between DSOs due to the cross-sectional dimension of their dataset. In contrast, we make use of a panel dataset and apply a difference-in-differences estimator with DSO fixed effects. Moreover, they do not consider the fact that DSOs with less than 30.000 customers are subject to a different type of price regulation.

In a theoretical setup, Cremer and Donder (2013) examine the effects of legal and ownership unbundling on grid investments. They find that, under ownership unbundling, the unregulated VIU limits its investments in grid capacity in order to increase equilibrium grid charges and maximize its profits from the grid operation. With legal unbundling the upstream firm takes downstream profits into account as well. Hence, given that downstream profits increase with grid capacity, the upstream firms invest more in grid capacity under legal unbundling and grid charges are lower. Similarly, Buehler et al. (2004) suggest that, under reasonable assumptions on demand, investment incentives turn out to be smaller under vertical separation than under vertical integration. The finding that ownership unbundling decreases investment is empirically supported by Gugler et al. (2013) in their examination of grid investments in European countries.

Several other papers have examined the effect of unbundling on retail prices in the energy sector . For the electricity sector, Steiner (2012) analysed a panel dataset of 19 OECD countries for the period of 1987-1996. Using a random effects estimator she finds that unbundling of generation and transmission had no significant effect on end-user prices. Sen and Jamasb (2012) use panel data for 19 Indian states between 1991 and 2007 and assess the effect of several regulatory variables on electricity prices for end-consumers and other variables. With respect to unbundling measures they do not find a significant effect on consumer prices. However, the paper does not provide any details on the type of unbundling. Nillesen and Pollitt (2011) 
investigate New Zealand's introduction of ownership unbundling of distribution from retail in 1998. They conduct a before-and-after analysis and find that average end-consumer prices did not change significantly after ownership unbundling, though residential prices increased and commercial prices decreased. For the gas sector, Growitsch and Stronzik (2014) and Brau et al. (2010) empirically analyze the effect of unbundling for a panel of EU countries. Both do not find that ownership unbundling had a significant effect on consumer prices for natural gas. However, Growitsch and Stronzik (2014) find that consumer prices were significantly reduced with legal unbundling.

A larger strand of the literature on vertical separation focuses on the empirical measurement of vertical economies, usually based on the estimation of a multi-output cost function, which are assumed to be lost with unbundling (e.g. Arocena et al., 2012; Fetz and Filippini, 2010; Greer, 2008; Gugler et al., 2017; Triebs et al., 2016). These papers highlight that vertical integration is associated with vertical synergies (e.g. coordination advantages, usage of common inputs and staff, sharing of information and hedging against risk, avoidance of double marginalization) and that successful unbundling has to outweigh the dissipated scope economies by its benefits (e.g. lower retail prices through competition, avoidance of cross-subsidization, mitigation of sabotage and discriminatory access in the network segment).

However, despite the costs increasing effect of unbundling due to the elimination of vertical economies there are also papers suggesting that there may be a countervailing effect due to an increase in cost efficiency. Using a cost function Nillesen and Pollitt (2011) analyze New Zealand's introduction of mandatory ownership unbundling of distribution from retail in 1998 and find that ownership unbundling has significantly reduced the unit-operation costs of electricity distribution and that grid quality (proxied by an electricity supply interruption index) has improved. Similar to Nillesen and Pollitt (2011), Filippini and Wetzel (2014) find that ownership unbundling improved the cost efficiency of New Zealand's DSOs based on Stochastic Frontier Analysis (which, in contrast to a standard cost function estimation, deals explicitly with firms' inefficiencies). A novel result is that the short-run efficiency improvement (evaluated from a variable cost function) is higher than the long-run efficiency (evaluated from a total cost function). Kwoka et al. (2010) derive efficiency scores of U.S. DSOs by data envelopment analysis and then apply a difference-in-differences approach to infer about how unbundling affects efficiency. The findings are that mandatory unbundling of the distribution grid from upstream generation had a decremental effect on efficiency, while voluntary divestiture did not 
significantly distort efficiency. These findings are in line with Delmas and Tokat (2005) who find that stronger integration leads to higher efficiency. A limitation of Kwoka et al.'s differencein-differences approach is that they do not provide any tests or evidence that the treatment (unbundling) and control (no unbundling) groups are similar.

Summed up, the effects of unbundling remains ambiguos according to the current literature. Regarding the competition fostering effects of unbundling, the scarce empirical evidence suggests that unbundling neither had a significant effect on grid charges nor on retail prices. However, the existing studies all suffer from different non-neglibible weaknesses. Moreover, it is not clear if the loss of vertical economies due to unbundling can be outweighed by an increased cost efficiency. Also, most studies focus on the effects of ownership unbundling while the effects of legal unbundling are clearly under-researched. This is suprising, especially against the background that legal unbundling represents the standard requirement in the energy sectors and is considered as a 'golden mean' between full ownership unbundling and vertical integration. (see, e.g. Höffler and Kranz, 2011b,a). Though the economies of vertical integration should be less affected by legal unbundling than by full ownership unbundling, it is also not clear if legal unbundling is still effective in reducing prices. Our paper naturally extends the literature by investigating the latter.

\section{Data}

We construct a panel dataset for the period 2005-2014, which combines information on grid charges and grid characteristics of German DSOs, renewable energy capacities connected to the grid, and - of utmost importance for our purpose - the status of DSOs' vertical integration. The data stem from several sources. Data on grid charges and grid characteristics are obtained from e'net, one of the largest private information service providers for Germany's energy industry. Data on all wind and solar plants, their capacities and their geographical location are gathered from EnergyMap, a project by the German branch of the International Solar Energy Society that combines and adjusts data on wind and solar capacities to the corresponding distribution grid. The integration of wind and solar plants to the grid is a major cost component for the DSOs, which is reflected in the grid charges. More renewables mean higher operational costs due to an increase in volatile and often unpredictable electricity feed-in and also higher replacement investments; more details follow below. 
Our main variable of interest is the status of vertical integration of the DSOs. Even though legal unbundling became mandatory for all DSOs with more than 100,000 customers, there were also cases where DSOs with less than 100,000 customers had to unbundle, for instance due to holdings in other grid operators. To identify the status of vertical integration, we manually skimmed the DSOs' financial statements of the respective sample years for announcements considering their form of unbundling as well as for information on their vertical structures, such as (the absence of) electricity generation or retail activities. If a utility's financial statement indicated legal unbundling, the legal connection to its former retail and/or generation unit was identified to double check the information contained in its financial statements. Furthermore, we determined if legally unbundled DSOs had implemented legal unbundling voluntarily by browsing their financial statements, homepages, and in many cases by contacting them via phone or e-mail.

We only consider DSOs with at least 30,000 customers in our application as the DSOs below this threshold are under a different regulation regime. ${ }^{11}$ There are also a few DSOs with slightly more than 30,000 customers that are regulated in the different regime due to historical regulatory excemptions. Those were excluded from our data. DSOs with more than 170,000 customers were also disregarded to avoid too large structural differences between DSOs. Finally, 122 DSOs remain in our sample. Out of the 122 DSOs, 46 have implemented legal unbundling, of which seven have unbundled voluntarily. None of them has implemented ownership unbundling. 77 DSOs in our dataset did not unbundle at all during our observation period 2005-2014. Hence, we observe (i) both states, legal unbundling and vertical integration for the 31 DSOs that unbundled after 2005, (ii) only the state of vertical integration for the 77 DSOs that did not unbundle at all, (iii) and only the state of legal unbundling for the 15 DSO that unbundled in 2005 or earlier. In Table 1 we provide more details on the distribution of the unbundling dates.

VIUs with more than 100.000 connected customers were required to incorporate legal unbundling according to Article 7 of the EnWG issued in 2005 (as outlined above). 20 of them unbundled before 2007 (17 of them in either 2005 or 2006) and 20 in 2007 or 2008 (19 of them in 2007) as shown in Table 1. Some utilities unbundled even later because they passed the threshold of 100,000 connected customers, either through organic growth or following a merger, and some even unbundled voluntarily.

\footnotetext{
${ }^{11}$ see Hellwig et al. (2018).
} 
Table 1: Timing of LU

\begin{tabular}{lccccccccc}
\hline Year & 2000 & 2004 & 2005 & 2006 & 2007 & 2008 & 2011 & 2013 & no LU \\
LU of DSOs & 2 & 1 & 12 & 5 & 19 & 1 & 3 & 3 & 77 \\
\hline
\end{tabular}

The data on grid charges are composed of a fixed component and a variable part that depends on the usage level. They are calculated for a representative residential household customer with an annual consumption of 4,000 kWh of electricity. As a robustness check, we also compute grid charges for an average business customer that consumes 50,000 kWh of electricity per year.

We also use information on the yearly maximum possible electricity generation capacity (in $\mathrm{kW}$ ) of the wind and solar plants connected to a DSO's distribution grid. These two variables are included to control for the additional time variation in costs imposed on DSOs by the connection of renewable energy sources (RES). In general, these costs are created due to the unreliable nature of RES and their expansion in recent years. More specifically, DSOs are responsible for the stability of the electricity grid. However, the grid stability can be endangered by grid congestions or voltage and frequency deviations. Therefore, DSOs need to use balancing power to counteract frequency deviations and redispatch measures or feed-in management to compensate grid congestions. As a result of the unpredictable nature of weather, an increase in the connected solar and wind capacity increases the risk of grid instability and therefore raises a DSO's expenses for the mentioned countervailing measures.

Furthermore, the existing grid is not designed to handle the high amount of locally generated electricity that results from the expansion of RES. Before the expansion of RES, electricity was typically received from a transmission system operator's extra-high voltage trans-regional transmission network and distributed by the responsible DSO in its grid area. However, the share of renewable energies on Germany's total electricity consumption increased from 15.1 percent in 2008 to 31.6 percent in 2015 and more than 90 percent of renewable energy plants were directly connected to the distribution grid in $2015 .{ }^{12}$ Therefore, not the whole amount of locally generated electricity can be locally consumed and thus needs to be distributed from the generation facility to a TSO's extra-high voltage transmission line. This creates additional investment costs, since the existing grid needs to be expanded to secure grid stability. Finally, DSOs are legally forced to connect newly built electricity plants under fair and objective conditions to their distribution grid according to $§ 20$ of the German Energy Act. Thus, each newly built

\footnotetext{
${ }^{12}$ See the monitoring reports of the Federal Ministry for Economic Affairs and Energy (Bundesnetzagentur, 2015, 2016).
} 
electricity plant creates additional investment costs if a grid expansion is needed to connect it. We also include population density per distribution grid area and the number of meter points (equivalent to the number of connected customers) into the set of control variables in order to consider the network usage and the grid size, respectively.

Table 2 provides descriptive sample statistics of our main variables employed in the regressions.

Table 2: Summary statistics

\begin{tabular}{lrrrrr}
\hline & Mean & SD & Min & Max & Obs \\
\hline Grid charge (€/4,000 kWh) & 208 & 32.7 & 105 & 320 & 832 \\
Meter points (\#) & 75,222 & 39,838 & 31,017 & 167,080 & 832 \\
Population density (\#) & 964 & 620 & 81 & 3,315 & 832 \\
Solar capacity (kW) & 17467 & 24,507 & 59 & 162,218 & 832 \\
Wind capacity (kW) & 7,907 & 18,911 & 0 & 133,217 & 832 \\
\hline
\end{tabular}

\section{$5 \quad$ Identification and Results}

We are interested in the effect of legal unbundling of VIUs on their grid charges (in the following simply prices). The suspicion is that VIUs may set higher prices in order to increase downstream costs for their competitors at the retail level while the integrated enterprise itself can crosssubsidize these costs. With legal unbundling this incentive should be mitigated by strengthening the independence of the DSOs. Thus, we would expect that DSOs decrease their prices once they are legally unbundled. If this is not the case, the VIUs either do not charge higher prices at all or legal unbundling is not effective in incentivizing DSOs against discriminatory behavior.

As we observe several VIUs that underwent the transition from vertical integration to legal unbundling during our period of investigation 2005-2014, we are able to perform a differencein-differences estimation. Formally, we estimate the following equation:

$$
\log \left(p_{i t}\right)=\beta \times L U_{i t}+\log \left(X_{i t}\right) \times \gamma+\xi_{i}+\xi_{t}+\epsilon_{i t},
$$

where $p_{i t}$ represents the grid charges set by DSO $i$ in year $t . L U_{i t}$ is our variable of interest and takes the value 1 if a firm $i$ is legally unbundled in year $t$ and 0 otherwise. $X$ is a set of (log-transformed) control variables, $\xi_{i}$ and $\xi_{t}$ are DSO and year fixed effects, and $\epsilon_{i t}$ represents the noise term. Finally, we cluster the standard errors at the DSO level.

An advantage of our data is that not all treated firms unbundled in the same year (see 
Table 1). This allows us to examine the effect for different control groups. The firms can be categorized into three different types of firms depending on their timing of unbundling:

(a) LU after 2005

For these firms the transition from vertical integration to legal unbundling takes place during our sample period. Hence, we observe their prices in years where they are still vertically integrated and in years where they are legally unbundled.

(b) $L U$ before 2006

These firms already unbundled before 2006. Hence, we do not observe pre-treatment prices for these firms as our sample period ranges from 2005 to 2014.

(c) NoLU

These firms did not legally unbundle at all during our sample period. For these firms we only observe prices for the status of vertical integration.

Hence, we have (a) as the treatment group and two different potential control groups (b) and $(c)$.

For a causal interpretation of $\beta$ in Equation 1 the parallel trend assumption must hold. It requires that the developments of the prices of the treatment and the control group would have been parallel in the absence of the treatment. However, it may be that VIUs that were obliged to legally unbundle their operations already had a different trend in their pricing before unbundling was implemented. For instance, their prices may have experienced a stronger increase or decrease, on average, than the prices of DSOs that were not forced to legally unbundle. ${ }^{13} \mathrm{In}$ this case, our estimates would be biased.

We can compare the pre-treatment development of prices of (a) with (c), but not with (b), given that our data set starts in 2005. However, for (a) and (c), Figure 1 suggests that the development of the prices of firms that unbundled and those that remained vertically integrated is indeed parallel before the treatment.

\footnotetext{
${ }^{13}$ Recall that the VIUs that had to unbundle are larger (more han 100.000 customers) and hence, differ from the VIUs that were allowed to remain vertically integrated in this regard.
} 


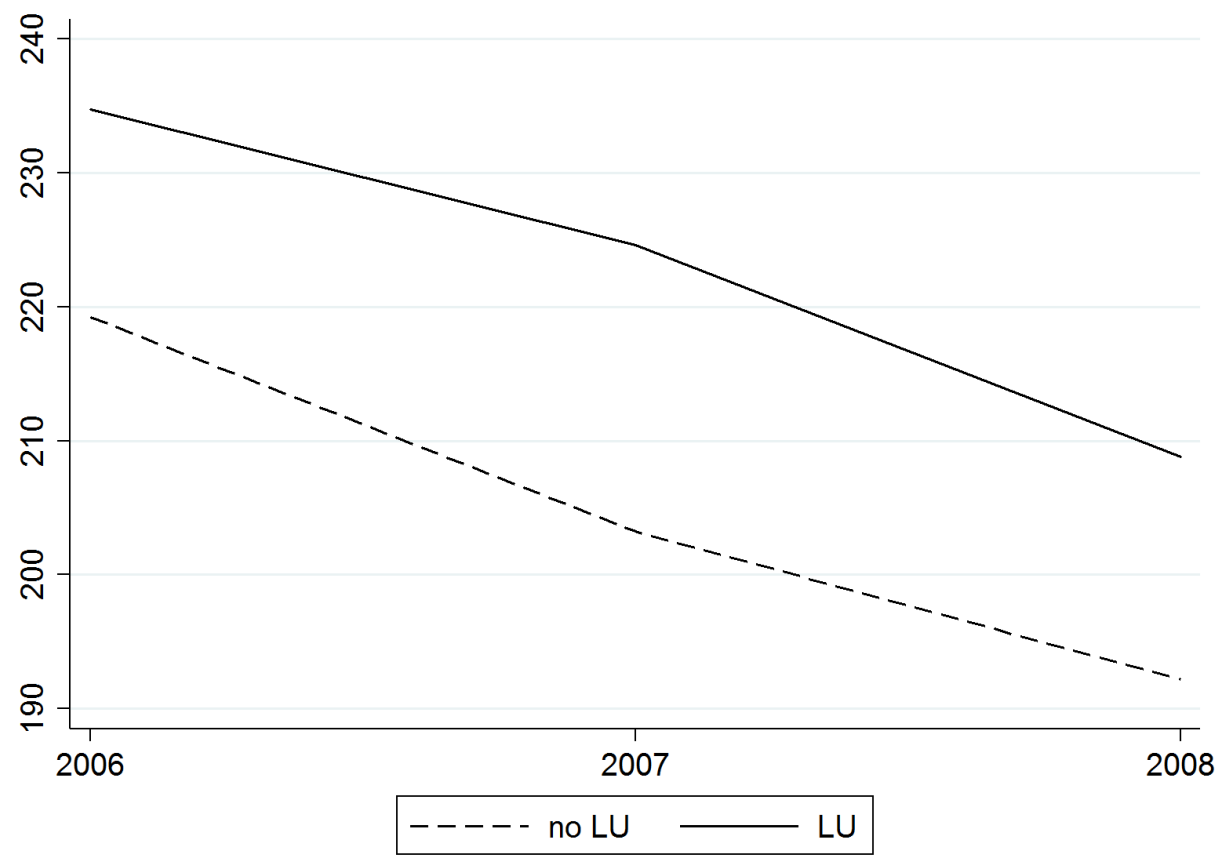

Figure 1: Pre-treatment development of prices of firms that unbundled and firms that did not

The firms that unbundled before 2006 account for one third of the unbundled firms (15 out of 46, 12 of them unbundled in 2005). However, it is reasonable to assume that the unbundling year was randomly chosen by these firms. In particular, we assume that firms that unbundled in 2005 had the same development of prices before they legally unbundled as the VIUs that unbdundled in 2006 or 2007. To add further confidence that this is the case, we compare if firms that unbundled before 2006 differ systematically from those that unbundled afterwards in their observable main characteristics: the number of connected customers (meter points), the population density in the DSOs' grid areas, and the installed wind and solar capacity per grid area.

To test this, we conduct a two-sample t-test of equal means of these charactersitics. Table 3 shows the results. The null hypothesis of equal means for both groups cannot be rejected for any of these characteristics, suggesting that the DSOs that unbundled before 2006 and those that unbundled afterwards do not differ statistically in this regard. This suggests that firms that unbundled before 2006 may also serve as a reasonable control group. ${ }^{14}$

\footnotetext{
${ }^{14} \mathrm{~A}$ further assumption is that the implementation of LU immediately translates into pricing. If this is not the case, we would not find a effect in the first one or two years after the LU implementation. However, we think it is realistic to assume that firms immediately adjust their pricing strategies once the link between the grid and the retail activities is cut.
} 
Table 3: t-test of equal means in the year 2006 of DSOs that legally unbundled before 2006 or after 2005

\begin{tabular}{cccc}
\hline & Mean & SD & t-test (p-value) \\
\hline METER POINTS & & & \\
LU before 2006 & 120,048 & 40,187 & \\
LU after 2005 & 100,748 & 41,728 & 0.24 \\
& & & \\
POPULATION DENSITY & & & \\
LU before 2006 & 2,547 & 1,761 & \\
LU after 2005 & 3,461 & 1,241 & 0.19 \\
& & & \\
WIND CAPACITY & & & \\
LU before 2006 & 8,168 & 11,957 & 0.22 \\
LU after 2005 & 3,528 & 4,905 & \\
& & & \\
SOLAR CAPACITY & & & \\
LU before 2006 & 2,579 & 3,583 & \\
LU after 2005 & 4,158 & 7,211 & \\
& & & 0.48 \\
\hline
\end{tabular}

Note: The $\mathrm{H}_{0}$ of the t-test is "means are equal for both groups (a) and (b)".

We now estimate Equation 1 for the different control groups. If both (b) and (c) are appropriate control groups, the effect of LU on prices should be similar. We will initially focus on the period 2005-2009. We do this to avoid that coincidental and potentially heterogeneous effects of a switch from rate-of-return regulation to incentive based regulation in 2009 affects our results. However, we will also consider the full period and explicitly account for this switch of the price regulation regime later.

In the first subsample, we include only firms that unbundled before 2009 and exclude all firms that unbundled after 2008 or not at all. Hence, the treatment group consists of the firms that experienced a transition from vertical integration to legal unbundling between 2006 and 2008 and the control group of all firms that unbundled earlier 2006 (as we do not observe their pre-treatment prices). For those firms we observe prices before and after LU was implemented. The results are reported in Column (1) of Table 4 and suggest that LU caused a price decrease of approximately $6.9 \% .^{15}$

In the second subsample, we only include firms that unbundled after 2005 or not at all. In other words, we replace the control group. While before it consisted of firms that are legally unbundled during the entire sample period, it now consists of firms that are vertically integrated

\footnotetext{
${ }^{15}$ To interpret the coefficients as percentage changes they are transformed to $100 \times \exp (\operatorname{coefficient})-1$, in this case $\exp (-0.072)-1=-0.069$.
} 
during the entire sample period. The treatment group remains the same as before, namely firms that unbundled during 2006-2008. The results are reported in Column (2) of Table 4. The effect of $\mathrm{LU}$ is now $5.4 \%(=\exp (-0.055)-1)$ and hence, similar in magnitude to that reported in Column $1 .^{16}$ This adds further confidence that the estimated effect is not due to different pre-treatment price developments.

Finally, we use the full sample of firms. The control group now consists of all firms that remained either vertically integrated or are legally unbundled in all sample years. The results are shown in Column (3) and suggest that LU causes an overall price reduction of around $5.9 \%$ $(=\exp (-0.061)-1)$.

Table 4: Estimating the effect of LU on different subsamples for the period 2005-2008

\begin{tabular}{lccc}
\hline DSOs included in Sample: & $\begin{array}{c}(1) \\
\text { LU before 2009 }\end{array}$ & $\begin{array}{c}(2) \\
\text { No LU or } \\
\text { LU after 2005 }\end{array}$ & $\begin{array}{c}(3) \\
\text { All DSOs }\end{array}$ \\
Dependent variable is $\log ($ price $)$ & & & \\
\hline LU & $-0.072^{* *}$ & $-0.055^{* *}$ & $-0.061^{* * *}$ \\
$\log$ (meter points) & $(0.036)$ & $(0.026)$ & $(0.022)$ \\
& -0.074 & $-0.205^{* * *}$ & $-0.194^{* * *}$ \\
$\log$ (population density) & $(0.109)$ & $(0.035)$ & $(0.027)$ \\
& $0.028^{* *}$ & 0.009 & 0.011 \\
$\log$ (solar capacity) & $(0.011)$ & $(0.012)$ & $(0.011)$ \\
$\log$ (wind capacity) & $0.104^{* * *}$ & 0.046 & $0.049^{*}$ \\
& $(0.028)$ & $(0.030)$ & $(0.028)$ \\
DSO FE & $0.082^{* * *}$ & -0.047 & 0.025 \\
Year FE & $(0.015)$ & $(0.054)$ & $(0.036)$ \\
& & & \\
Observations & Yes & Yes & Yes \\
\hline
\end{tabular}

Note: Standard errors clustered at the DSO level in parenthesis. Period of investigation is restricted to $2005-2008$ (i.e. before the regime switch from rate-of-return regulation to incentive regulation). ${ }^{* * *} p<1 \%,{ }^{* *} p<5 \%,{ }^{*} p<10 \%$.

\subsection{Interaction of the status of vertical integration with price regulation}

As mentioned before, we are also interested in how the effect of LU on prices depends on the type of price regulation in place. To study this, we take advantage of a regulatory reform, which took place in 2009 - a switch from rate-of-return regulation to incentive-based regulation (see

\footnotetext{
${ }^{16}$ We evaluate the difference between the estimated coefficients in Column $1\left(\hat{\beta}_{(1)}\right)$ and $2\left(\hat{\beta}_{(2)}\right)$ based on a z-value: $z=\left(\hat{\beta}_{(1)}-\hat{\beta}_{(2)}\right) / \sqrt{S E\left(\hat{\beta}_{(1)}\right)^{2}+S E\left(\hat{\beta}_{(2)}\right)}=(-0.072+0.055) / \sqrt{\left(0.036^{2}-0.026^{2}\right)}=-0.38$ (Clogg et al., 1995). The critical value for the $90 \%$ significance value is -1.96 , so we cannot reject the $\mathrm{H}_{0}$ of equal coefficients. Thus, the two estimated coefficients are statistically not distinguishable.
} 
Section 2). We therefore apply a triple-differences approach and estimate the following model:

$$
\log \left(p_{i t}\right)=\beta_{1} \times L U_{i t}+\beta_{2} \times L U_{i t} \times I R_{t}+\log \left(X_{i t}\right) \times \gamma+\xi_{i}+\xi_{t}+\epsilon_{i t}
$$

where $I R$ takes a value of 1 during the time of incentive regulation from 2009 on, and is 0 before 2009. As we now explicitly account for the regulatory reform, we can make use of the entire observation period 2005-2014 in this regression.

The results from estimating Equation 2 are presented in Column (3) of Table 5. The effect of LU is similar as before and suggests that LU causes a price decrease of $5.35 \%(=100 \times(\exp (-$ 0.055)-1)) under rate-of-return regulation. Moreover, the estimate of the interaction term $L U \times I R$ suggests that the switch from rate-of-return regulation to incentive regulation causes an additional price decrease of $3.34 \%(=100 \times(\exp (-0.034)-1))$ for legally unbundled utilities compared to vertically integrated ones. In sum, under incentive regulation, prices are $8.69 \%$ lower for legally unbundled than for vertically integrated utilities. ${ }^{17}$ This suggests that the type of price regulation indeed matters regarding the efficacy of LU and that the price effect of LU comes particularly into play under incentive regulation.

In addition to the fixed-effects model, as given in equation (2), we also estimate a model in which we replace the year fixed effects $\xi_{t}$ by a yearly time trend $(T)$ and its squared term $\left(T^{2}\right)$. Although this specification may be less precise (i.e. time fixed effects are more flexible than the polynomial time trend), it has the advantage that it additionally allows us to estimate the effect of the introduction of the incentive regulation, which would otherwise be captured by the year fixed effects:

$$
\begin{aligned}
\log \left(p_{i t}\right) & =\beta_{1} \times L U_{i t}+\beta_{3} \times I R_{t} \\
& +\log \left(X_{i t}\right) \times \gamma+\delta_{1} T+\delta_{2} T^{2}+\xi_{i}+\epsilon_{i t} .
\end{aligned}
$$

The results are shown in Column (4) of Table 5 and are fully robust to the fixed-effects results as in Column (3). We find a price decrease of $4.7 \%(=100 \times(\exp (-0.048)-1))$ following the implementation of LU. Again, the parameter estimate for the interaction term $L U \times I R$ suggests that under incentive regulation there is an additional price effect for legally unbundled utilities in the magnitude of $-3.44 \%(=100 \times(\exp (-0.035)-1))$ compared to firms that remained vertically integrated. As all coefficients in Column (4) have similar magnitudes as the estimates

\footnotetext{
${ }^{17}$ The combined effect of $L U$ and $L U \times I R$ is computed as $100 \times(\exp (-0.055)-1+\exp (-0.034)-1)=-5.35+(-$ $3.34)=-8.69$.
} 
in Column (3), the quadratic trend appears to mimic the year fixed effects reasonably.

Table 5: Estimating the effect of LU and IR for the period 2005-2014

\begin{tabular}{lcccc}
\hline & $(1)$ & $(2)$ & $(3)$ & $(4)$ \\
Dependent variable is $\log ($ price $)$ & & & & \\
\hline LU & $-0.078^{* * *}$ & $-0.077^{* * *}$ & $-0.055^{* *}$ & $-0.048^{* *}$ \\
& $(0.019)$ & $(0.021)$ & $(0.023)$ & $(0.023)$ \\
IR & & & & $0.049^{* * *}$ \\
& & & & $(0.010)$ \\
LU $\times$ IR & & & $-0.034^{* *}$ & $-0.035^{* *}$ \\
& & & $(0.017)$ & $(0.018)$ \\
$\log ($ meter points) & $-0.153^{* *}$ & $-0.149^{* *}$ & $-0.161^{* *}$ & $-0.155^{* *}$ \\
& $(0.069)$ & $(0.070)$ & $(0.068)$ & $(0.068)$ \\
$\log ($ population density) & -0.005 & -0.008 & -0.004 & -0.007 \\
& $(0.006)$ & $(0.008)$ & $(0.008)$ & $(0.007)$ \\
$\log ($ solar capacity) & 0.008 & 0.012 & 0.008 & 0.009 \\
& $(0.010)$ & $(0.012)$ & $(0.013)$ & $(0.012)$ \\
$\log ($ wind capacity) & $0.009^{* * *}$ & $0.008^{* * *}$ & $0.009^{* * *}$ & $0.008^{* * *}$ \\
& $(0.003)$ & $(0.003)$ & $(0.003)$ & $(0.003)$ \\
DSO Fixed Effects & & & & \\
Year Fixed Effects & $\mathrm{Y}$ & $\mathrm{Y}$ & $\mathrm{Y}$ & $\mathrm{Y}$ \\
Time trend (T \& T $\left.{ }^{2}\right)$ & $\mathrm{Y}$ & $\mathrm{N}$ & $\mathrm{Y}$ & $\mathrm{N}$ \\
& $\mathrm{N}$ & $\mathrm{Y}$ & $\mathrm{N}$ & $\mathrm{Y}$ \\
Observations & & & & \\
\hline Note: Standard errors clustered at the DSO level in parenthesis. & ${ }^{* * *} p<1 \%{ }^{* *} p<5 \%$, \\
${ }^{*} p<10 \%$. & & & &
\end{tabular}

The estimates suggest that prices for vertically integrated firms are approximately 5\% $(=100 \times(\exp (0.049)-1))$ higher under incentive regulation than under rate-of-return regulation. In contrast, we do not find that the type of price regulation affects pricing of legally unbundled firms as the combined effect of $I R$ and $L U \times I R$ is only $1.58 \%(=(\exp (-0.049)-1+$ $\exp (-0.035)-1))$, and statistically insignificant. ${ }^{18}$ Hence, our estimates suggest that vertically integrated firms increased their prices due to the switch from rate-of return regulation, while it had no effect for legally unbundled firms.

We also estimate the models without consideration of the introduction of the regulatory reform. The results are reported in columns 1 and 2 of Table 5. They suggest that without consideration of the price regulation regime, legal unbundling reduces prices by approximately $8 \%$ compared to vertical integration.

A concern may be that grid charges are non-linear in consumption as they are two-part tariffs

\footnotetext{
${ }^{18} \mathrm{~A}$ t-test with the null hypothesis $\beta_{2}+\beta_{3}=0$ gives a p-value of 0.39 , indicating that the effect is not distinguishable from zero.
} 
consisting of a fixed component and a per-unit charged component. To check the robustness of the estimates we also estimated the specifications from Table 5 for business consumers with a yearly electricity consumption of 50,000 kwh. The results are fully robust and are reported in Appendix Table A1.

\subsection{Endogeneity}

There may be concerns about endogeneity. One issue is that seven firms in our dataset unbundled voluntarily and hence self-selection into treatment may have an effect on our results. To test this, we exclude the seven voluntarily unbundled DSOs from our dataset and estimate the specifications from Table 5 again. The results stay robust as shown in Table 6 .

Table 6: Estimation of the effect of LU and IR for the period 2005-2014 after exclusion of voluntarily unbundled DSOs

\begin{tabular}{lcccc}
\hline & $(1)$ & $(2)$ & $(3)$ & $(4)$ \\
Dependent variable is $\log ($ price $)$ & & & & \\
\hline LU & $-0.079^{* * *}$ & $-0.080^{* * *}$ & $-0.062^{* * *}$ & $-0.055^{* *}$ \\
& $(0.019)$ & $(0.021)$ & $(0.023)$ & $(0.023)$ \\
IR & & & & $0.049^{* * *}$ \\
& & & & $(0.010)$ \\
LU $\times$ IR & & & -0.027 & -0.027 \\
& & & $(0.017)$ & $(0.018)$ \\
$\log ($ meter points $)$ & $-0.154^{* *}$ & $-0.150^{* *}$ & $-0.160^{* *}$ & $-0.154^{* *}$ \\
& $(0.070)$ & $(0.072)$ & $(0.070)$ & $(0.071)$ \\
$\log ($ population density) & -0.000 & -0.003 & -0.000 & -0.003 \\
& $(0.005)$ & $(0.006)$ & $(0.006)$ & $(0.006)$ \\
$\log ($ solar capacity) & 0.003 & 0.008 & 0.003 & 0.005 \\
& $(0.010)$ & $(0.011)$ & $(0.013)$ & $(0.012)$ \\
$\log ($ wind capacity) & $0.008^{* * *}$ & $0.007^{* *}$ & $0.007^{* * *}$ & $0.006^{* *}$ \\
& $(0.003)$ & $(0.003)$ & $(0.002)$ & $(0.003)$ \\
DSO Fixed Effects & & & & \\
Year Fixed Effects & $\mathrm{Y}$ & $\mathrm{Y}$ & $\mathrm{Y}$ & $\mathrm{Y}$ \\
Time trend (T \& T $\left.{ }^{2}\right)$ & $\mathrm{Y}$ & $\mathrm{N}$ & $\mathrm{Y}$ & $\mathrm{N}$ \\
& $\mathrm{N}$ & $\mathrm{Y}$ & $\mathrm{N}$ & $\mathrm{Y}$ \\
Observations & & & & 723 \\
\hline Note: Standard errors clustered at the DSO level in parenthesis. & ${ }^{* * *} p<1 \%,{ }^{* *} p<5 \%$, \\
${ }^{*} p<10 \%$. & & & &
\end{tabular}

Moreover, it is also possible that some VIUs may have sold parts of their grid prior to the introduction of the legal unbundling regime in order to prevent mandatory legal unbundling. Hence, excluding the voluntarily unbundled VIUs may not be sufficient to fully exclude potential 
bias due to endogeneity arising from self-selection into treatment. To address this concern further, we apply the identification strategy recently proposed by Lewbel $(2012,2018)$.

Table 7: Lewbel (2012) IV estimation of the effect of LU and IR for the period 2005-2014

\begin{tabular}{|c|c|c|c|c|}
\hline Dependent variable is $\log$ (price) & (1) & $(2)$ & $(3)$ & $(4)$ \\
\hline $\mathrm{LU}$ & $\begin{array}{c}-0.088^{* * *} \\
(0.025)\end{array}$ & $\begin{array}{c}-0.085^{* * *} \\
(0.027)\end{array}$ & $\begin{array}{c}-0.064^{* *} \\
(0.025)\end{array}$ & $\begin{array}{r}-0.059^{* *} \\
(0.026)\end{array}$ \\
\hline IR & & & & $\begin{array}{c}0.052^{* * *} \\
(0.011)\end{array}$ \\
\hline $\mathrm{LU} \times \mathrm{IR}$ & & & $\begin{array}{c}-0.038^{* *} \\
(0.017)\end{array}$ & $\begin{array}{r}-0.045^{* *} \\
(0.018)\end{array}$ \\
\hline $\log ($ meter points $)$ & $\begin{array}{c}-0.155^{* *} \\
(0.073)\end{array}$ & $\begin{array}{c}-0.149^{* *} \\
(0.071)\end{array}$ & $\begin{array}{c}-0.163^{* *} \\
(0.068)\end{array}$ & $\begin{array}{r}-0.158^{* *} \\
(0.067)\end{array}$ \\
\hline $\log$ (population density) & $\begin{array}{l}-0.004 \\
(0.008)\end{array}$ & $\begin{array}{l}-0.007 \\
(0.008)\end{array}$ & $\begin{array}{l}-0.003 \\
(0.008)\end{array}$ & $\begin{array}{l}-0.006 \\
(0.007)\end{array}$ \\
\hline $\log ($ solar capacity $)$ & $\begin{array}{c}0.009 \\
(0.013)\end{array}$ & $\begin{array}{c}0.012 \\
(0.011)\end{array}$ & $\begin{array}{c}0.008 \\
(0.013)\end{array}$ & $\begin{array}{c}0.009 \\
(0.012)\end{array}$ \\
\hline $\log ($ wind capacity) & $\begin{array}{c}0.009^{* * *} \\
(0.003)\end{array}$ & $\begin{array}{c}0.008^{* * *} \\
(0.003)\end{array}$ & $\begin{array}{c}0.009^{* * *} \\
(0.003)\end{array}$ & $\begin{array}{c}0.008^{* * *} \\
(0.003)\end{array}$ \\
\hline DSO Fixed Effects & $\mathrm{Y}$ & $\mathrm{Y}$ & $\mathrm{Y}$ & Y \\
\hline Year Fixed Effects & $\mathrm{Y}$ & $\mathrm{N}$ & $\mathrm{Y}$ & $\mathrm{N}$ \\
\hline Time trend $\left(\mathrm{T} \& \mathrm{~T}^{2}\right)$ & $\mathrm{N}$ & $\mathrm{Y}$ & $\mathrm{N}$ & $\mathrm{Y}$ \\
\hline $\begin{array}{l}\text { First-stage Wald test for group } \\
\text { heteroskedasticity (p-val.) }\end{array}$ & 0.00 & 0.00 & 0.00 & 0.00 \\
\hline First-stage F stat. & 364.21 & 48.19 & - & - \\
\hline Kleibergen-Paap F stat. & - & - & 74.85 & 37.88 \\
\hline $\begin{array}{l}\text { Critical value for weak instruments }(10 \%) \\
\text { by Stock and Yogo }\end{array}$ & 11.52 & 11.12 & 11.06 & 10.89 \\
\hline Hansen J stat. (p-val.) & 0.70 & 0.34 & 0.52 & 0.75 \\
\hline Durbin-Wu-Hausman test & 0.42 & 0.73 & 0.34 & 0.70 \\
\hline Observations & 778 & 778 & 778 & 778 \\
\hline
\end{tabular}

Note: Standard errors corrected for using generated instruments and clustered at the DSO level in parenthesis. $L U$ and $I R \times L U$ treated es endogenous and are instrumented using Lewbel's (2012) heteroskedasticity based IV approach. Estimation is done by GMM. ${ }^{* * *} p<1 \%,{ }^{* *} p<5 \%,{ }^{*} p<10 \%$.

Lewbel (2012) provides an estimator for linear regression models containing an endogenous regressor, when no outside instrument is available. In a nutshell, the method works by exploiting the model heteroskedasticity to construct instruments using the available regressors. Lewbel (2018) shows that the assumptions required for the proposed estimator can also be satisfied when an endogenous regressor is binary, as is the case with our LU variable. The results of the 
Lewbel IV estimations are reported in Table $7 .{ }^{19}$

As Lewbel (2012) shows, the model is identified if the errors from a regression of the endogenous variable on covariates from the main model are heteroskedastic and the variance of these errors is correlated with at least some of the covariates but not with the covariances of these errors and the second stage errors. We test the heteroskedasticity requirement based on the residuals of the first stage regression, using a modified Wald statistic for groupwise heteroskedasticity. The test leads us to reject the null hypotheses of constant variance as can be seen in Table 7. Table 7 also shows that the generated instruments are sufficiently strong to identify the LU variables according to the First-Stage F-statistic and the Kleibergen-Paap F-statistic as the Stock and Yogo (2005) critical values are always exceeded. The instruments are also not correlated with the error term as shown by the Hansen $J$ test. The Durbin-Wu-Hausman test does not point towards an endogeneity issue as it does not reject the exogeneity hypothesis of the unbundling introduction. Nevertheless, the results turn out to be consistent with the estimations presented earlier, supporting our main results.

\subsection{Placebo}

Finally, we conduct a placebo test to exclude other possibilities that could drive our results. As discussed earlier, an important assumption for the validity of our difference-in-differences estimation is that prices in the treatment and the control group have a common trend in the absence of LU. Since we have already shown that the effect of LU is similar for different control groups, our estimated effect is unlikely to be caused by different trends.

Another common concern in difference-in-difference estimation is that the standard errors may understate the standard deviation of the estimators due to serial correlation (Bertrand et al., 2004). As with the previous concern, this concern is also unlikely in our case, because we allow for arbitrary serial correlation by clustering standard errors at the utility level.

In any event, we formally examine this concern by randomly assigning a placebo LU year to each utility that implemented LU during our sample period. We then run the specification as given in Equation 2 and compare the resulting coefficients of the LU dummy with the actual LU coefficient from Column (3) in Table 5. We repeat this procedure 1,000 times. Figure 2 shows the distribution of the resulting placebo coefficients and their p-values. The placebo coefficients are centered around zero (the mean is 0.003 ) and their p-values exceed $10 \%$ in $89.5 \%$

\footnotetext{
${ }^{19} \mathrm{~A}$ technical description of the required assumptions for the Lewbel IV estimation and a brief description on the procedure itself are provided in the Online Appendix.
} 
of the cases. Moreover, the p-values of the placebo coefficients exceed the true p-value of our actual LU coefficient in $97.3 \%$ of the cases. ${ }^{20}$ This is very close to random chance and suggests that our results are indeed not caused by a violation of the common trends assumption or by autocorrelation.

Figure 2: Placebo results
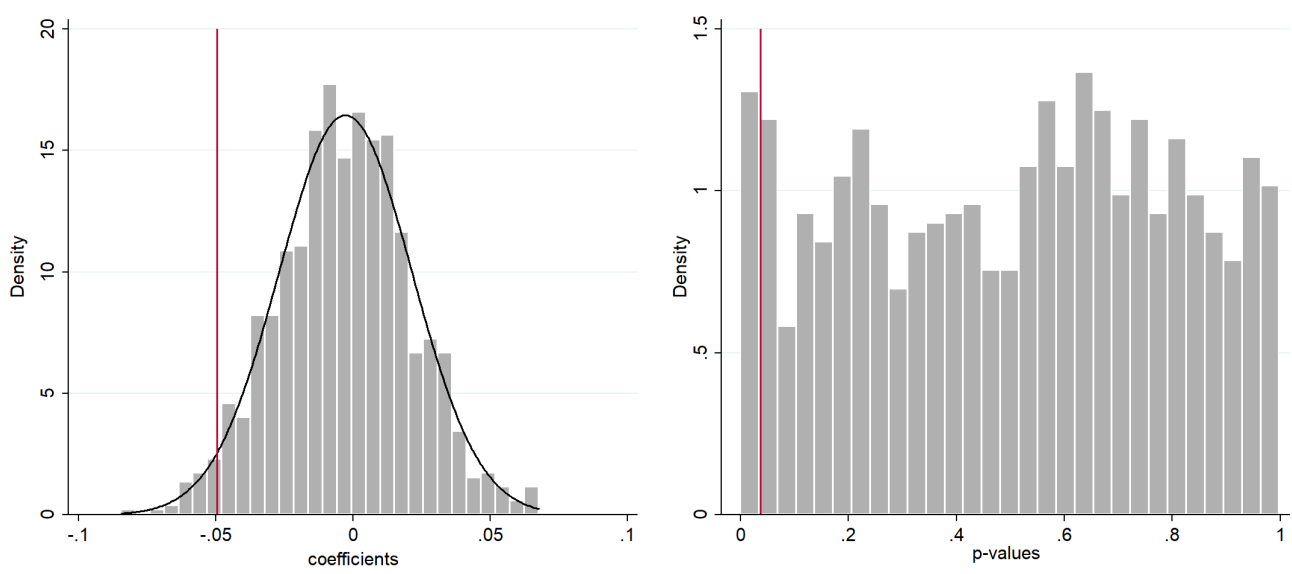

The left panel presents distribution of the placebo coefficients (1,000 repetitions), the right panel the distribution of the corresponding p-values. The red vertical lines present the values from the estimation in Column (3) of Table 5. The Black solid line illustrates a normal distribution.

\section{Conclusion and Policy Implications}

Unbundling of vertically integrated utilities is applied in many jurisdictions around the globe in network industries such as energy, telecommunications, broadband internet, and railway transportation. The idea of unbundling is to separate the natural monopoly (usually the network) from other segments in the vertical supply chain, aiming at fostering competition and reducing incentives to discriminate against competitors with third-party access to the network.

Despite the relevance of unbundling given its wide practical implementation, its actual efficacy is still ambiguous and debated controversially. There is a consensus in the literature that unbundling is associated with a loss of vertical scope economies, which is most pronounced for full ownership unbundling. Also, the empirical literature on the deemed competitive effects of unbundling is unfortunately scarce and has not identified a price decreasing effect on grid charges or retail prices.

In this paper we analyze the effect of legal unbundling on grid charges using a panel dataset of German electricity utilities, of which some underwent legal unbundling while others did not.

\footnotetext{
${ }^{20}$ The p-value of LU's coefficient estimate from Column 3 in Table 5 is 0.017.
} 
Moreover, during our sample period 2005-2014, we observe a switch in the regulatory regime from rate-of-return to incentive regulation which additionally enables us to identify the effect of unbundling on grid charges under different price reguation regimes. Legal unbundling is the standard requirement for unbundling in the energy sectors and is supposed to be a 'golden mean' between vertical integration and full ownership unbundling (Höffler and Kranz, 2011a,b). It is considered to diminish vertical scope economies less than ownership unbundling but to similarly reduce the incentives of the network operator to distort downstream competition. However, it is particularly not clear if the latter effects actually translates into practice.

We find that legal unbundling is indeed successful in reducing grid charges by around 5\% to $9 \%$, depending on the type of price regulation in place. While legally unbundled utilities subject to rate-of-return regulation charge around $5 \%$ lower grid charges compared to VIU, under incentive regulation the prices are even around $9 \%$ lower. Our findings are important because we extend the relatively limited literature on the potential benefits of unbundling in general and of legal unbundling in particular. Our findings alleviate the concerns of a broader strand of literature (e.g. Arocena et al., 2012; Gugler et al., 2017; Triebs et al., 2016), which finds that unbundling destroys scope economies, and we contrast previous empirical work that does not find an effect of legal unbundling on distribution grid charges in Germany (Nikogosian and Veith, 2012).

Fortunately, the combination of legal unbundling together with incentive regulation is applied widely in electricity and gas distribution markets in the EU Member States and the USA. For other countries, such as Japan, that are about to follow this avenue, our results bear promising expectations. Another relevant issue is that in the EU, only the minority of relatively large electricity and gas utilities with more than 100,000 customers are required to legally unbundle. To benefit from the price effects of legal unbundling, policymakers may want to loosen this stringency. 


\section{References}

Arocena, P., Saal, D.S., Coelli, T., 2012. Vertical and horizontal scope economies in the regulated U.S. electric power industry. The Journal of Industrial Economics 60, 434-467.

Bertrand, M., Duflo, E., Mullainathan, S., 2004. How much should we trust differences-indifferences estimates? The Quarterly Journal of Economics 119, 249-275.

Bourreau, M., Doğan, P., 2005. Unbundling the local loop. European Economic Review 49, 173-199.

Brau, R., Doronzo, R., Florio, C.V., Florio, M., 2010. Eu gas industry reforms and consumers' prices. The Energy Journal 31.

Buehler, S., Schmutzler, A., Benz, M.A., 2004. Infrastructure quality in deregulated industries: Is there an underinvestment problem? International Journal of Industrial Organization 22, $253-267$.

Bundesnetzagentur, 2015. Monitoring report 2015.

Bundesnetzagentur, 2016. Monitoring report 2016.

CEER, 2013. Status review on the transposition of unbundling requirements for dsos and closed distribution system operators. Council of European Energy Regulators (CEER) Conclusions Paper, Ref: C12-UR-47-03.

Clogg, C.C., Petkova, E., Haritou, A., 1995. Statistical methods for comparing regression coefficients between models. American Journal of Sociology 100, 1261-1293.

Cremer, H., Crémer, J., Donder, P.D., 2006. Legal vs ownership unbundling in network industries. CEPR Discussion Paper No. 5767.

Cremer, H., Donder, P.D., 2013. Network investment under legal and ownership unbundling. Review of Network Economics 12.

Delmas, M., Tokat, Y., 2005. Deregulation, governance structures, and efficiency: the U.S. electric utility sector. Strategic Management Journal 26, 441-460.

Fetz, A., Filippini, M., 2010. Economies of vertical integration in the Swiss electricity sector. Energy Economics 32, 1325-1330. 
Filippini, M., Wetzel, H., 2014. The impact of ownership unbundling on cost efficiency: Empirical evidence from the New Zealand electricity distribution sector. Energy Economics 45, $412-418$.

Finger, M., 2014. Governance of competition and performance in European railways: An analysis of five cases. Utilities Policy 31, 278-288.

Greer, M.L., 2008. A test of vertical economies for non-vertically integrated firms: The case of rural electric cooperatives. Energy Economics 30, 679-687.

Growitsch, C., Stronzik, M., 2014. Ownership unbundling of natural gas transmission networks: empirical evidence. Journal of Regulatory Economics 46, 207-225.

Gugler, K., Liebensteiner, M., 2018. Productivity growth and the general X-factor in Austria's gas distribution. Vienna University of Economics and Business, Working Paper.

Gugler, K., Liebensteiner, M., Schmitt, S., 2017. Vertical disintegration in the European electricity sector: Empirical evidence on lost synergies. International Journal of Industrial Organization 52, 450-478.

Gugler, K., Rammerstorfer, M., Schmitt, S., 2013. Ownership unbundling and investment in electricity markets: A cross country study. Energy Economics 40, 702-713.

Hellwig, M., Schober, D., Cabral, L., 2018. Incentive regulation: Evidence from German electricity networks. Centre for European Economic Research (ZEW), Discussion Paper No. 18-010.

Höffler, F., Kranz, S., 2011a. Imperfect legal unbundling of monopolistic bottlenecks. Journal of Regulatory Economics 39, 273-292.

Höffler, F., Kranz, S., 2011b. Legal unbundling can be a golden mean between vertical integration and ownership separation. International Journal of Industrial Organization 29, 576-588.

Kwoka, J., Pollitt, M., Sergici, S., 2010. Divestiture policy and operating efficiency in U.S. electric power distribution. Journal of Regulatory Economics 38, 86-109.

Lewbel, A., 2012. Using heteroscedasticity to identify and estimate mismeasured and endogenous regressor models. Journal of Business and Economic Statistics 30, 67-80.

Lewbel, A., 2018. Identification and estimation using heteroscedasticity without instruments: The binary endogenous regressor case. Economics Letters 165, 10-12. 
Monopoly Commission, 2011. Energie 2011: Wettbewerbsentwicklung mit Licht und Schatten. Sondergutachten 59 .

Monopoly Commission, 2015. Energie 2015: Ein wettbewerbliches Marktdesign für die Energiewende. Sondergutachten 71 .

Nardotto, M., Valletti, T., Verboven, F., 2015. Unbundling the incumbent: Evidence from UK broadband. Journal of the European Economic Association 13, 330-362.

Nikogosian, V., Veith, T., 2012. Vertical integration, separation and non-price discrimination: An empirical analysis of German electricity markets for residential customers. Centre for European Economic Research (ZEW), Discussion Paper No. 11-069.

Nillesen, P.H.L., Pollitt, M.G., 2011. Ownership unbundling in electricity distribution: Empirical evidence from New Zealand. Review of Industrial Organization 38, 61-93.

Pindyck, R.S., 2007. Mandatory unbundling and irreversible investment in telecom networks. Review of Network Economics 6.

RAP, 2014. Netzentgelte in Deutschland: Herausforderungen und Handlungsoptionen. The Regulatory Assistance Project (RAP): Study commissioned by Agora Energiewende, Version 1.01 .

Sen, A., Jamasb, T., 2012. Diversity in unity: An empirical analysis of electricity deregulation in indian states. The Energy Journal 33.

Steiner, F., 2012. Regulation, industry structure and performance in the electricity supply industry. OECD Economic Studies 32, 143-182.

Stock, J.H., Yogo, M., 2005. Testing for weak instruments in linear iv regression, in: Finger, M., Messulam, P. (Eds.), Identification and Inference for Econometric Models: Essays in Honor of Thomas Rothenberg. Cambridge University Press, Cambridge, UK. chapter 5, pp. 80-108.

Triebs, T.P., Saal, D.S., Arocena, P., Kumbhakar, S.C., 2016. Estimating economies of scale and scope with flexible technology. Journal of Productivity Analysis 45, 173-186.

van de Velde, D., 2015. European railway reform: unbundling and the need for coordination, in: Finger, M., Messulam, P. (Eds.), Rail Economics, Policy and Regulation in Europe. Edward Elgar Publishing, Cheltenham, pp. 52-88. 


\section{Appendix}

\section{A Analysis for Business Customers}

Table A1: Estimating the effect of LU and IR for the period 2006-2014:

Estimation for business customers with a yearly electricity consumption of 50,000 kWh

\begin{tabular}{lcccc}
\hline & $(1)$ & $(2)$ & $(3)$ & $(4)$ \\
Dependent variable is $\log ($ price $)$ & & & & \\
\hline LU & $-0.079^{* * *}$ & $-0.079^{* * *}$ & $-0.050^{* *}$ & $-0.045^{*}$ \\
& $(0.020)$ & $(0.021)$ & $(0.023)$ & $(0.023)$ \\
IR & & & & $0.055^{* * *}$ \\
& & & & $(0.012)$ \\
LU×IR & & & $-0.043^{* *}$ & $-0.043^{* *}$ \\
& & & $(0.019)$ & $(0.019)$ \\
$\log ($ meter points) & -0.099 & -0.095 & -0.108 & -0.103 \\
& $(0.073)$ & $(0.074)$ & $(0.074)$ & $(0.074)$ \\
$\log ($ population density) & -0.003 & -0.006 & -0.002 & -0.006 \\
& $(0.006)$ & $(0.008)$ & $(0.008)$ & $(0.008)$ \\
solar capacity) & 0.010 & 0.014 & 0.009 & 0.012 \\
& $(0.010)$ & $(0.012)$ & $(0.014)$ & $(0.013)$ \\
$\log ($ wind capacity) & $0.011^{* * *}$ & $0.010^{* * *}$ & $0.011^{* * *}$ & $0.010^{* * *}$ \\
& $(0.003)$ & $(0.003)$ & $(0.003)$ & $(0.003)$ \\
DSO Fixed Effects & & & & \\
Year Fixed Effects & $\mathrm{Y}$ & $\mathrm{Y}$ & $\mathrm{Y}$ & $\mathrm{Y}$ \\
Time trend (T \& T $\left.{ }^{2}\right)$ & $\mathrm{Y}$ & $\mathrm{N}$ & $\mathrm{Y}$ & $\mathrm{N}$ \\
Observations & $\mathrm{N}$ & $\mathrm{Y}$ & $\mathrm{N}$ & $\mathrm{Y}$ \\
\hline
\end{tabular}

Note: Standard errors clustered at the DSO level in parenthesis. ${ }^{* * *} p<1 \%,{ }^{* *} p<5 \%$, ${ }^{*} p<10 \%$. 


\section{B Technical description of Lewbel's (2012) IV method}

Consider the linear relationship $Y=X \beta+Z \gamma+\varepsilon_{1}$, where $Z$ is the potentially endogenous variable (the LU dummy in our case) and $\gamma$ is the parameter we wish to estimate. The equation that determines $Z$ is $Z=X \alpha+\varepsilon_{2}$, where $\varepsilon_{1}$ and $\varepsilon_{2}$ may be correlated and no element of $X$ can be used as an instrument, i.e. there is no outside instrument available. As usual, the requirement is that $E\left(X \varepsilon_{1}\right)=0, E\left(X_{i} \varepsilon_{2}\right)=0$, and that $E\left(X X^{\prime}\right)$ is nonsingular. The additional assumptions for the identification in the absence of an outside instrument are that $\operatorname{Cov}\left(X, \varepsilon_{1} \varepsilon_{2}\right)=0$ and that there is some heteroskedasticity in the error of the first-stage, $\operatorname{Cov}\left(X, \varepsilon_{2}^{2}\right) \neq 0$. The variation in $\varepsilon_{2}$ can then be used to identify $X$. If these assumptions hold, $\gamma$ (and $\beta$ ) can be estimated consistently by using interactions of the mean-centered control variables and the residuals $\left((X-\bar{X}) \hat{\varepsilon}_{2}\right)$ to instrument for $Z$.

The estimation procedure is then as follows:

1. Estimate $\hat{\alpha}$ by an OLS regression of $X$ on $Z$ to obtain $\hat{\varepsilon}_{2}=Z-X \hat{\alpha}$.

2. Use the interactions of the residuals $\hat{\varepsilon}_{2}$ and the mean-centered covariates $(X-\bar{X})$ as instruments for $Z$ and estimate $Z=X \alpha+\gamma(X-\bar{X}) \hat{\varepsilon}_{2}+\varepsilon_{3}$.

3. Obtain $\hat{\beta}$ and $\hat{\gamma}$ by estimating $Y=X \beta+\hat{Z} \gamma+\varepsilon_{4}$. 